\title{
Fat structure and composition in human milk and infant formulas: Implications in infant health
}

\author{
Vipul Mehrotra $^{\mathrm{a}}$, Sunil Kumar Sehgal ${ }^{\mathrm{b}}$, Nikhil Rajeev Bangale ${ }^{\mathrm{c}, *}$

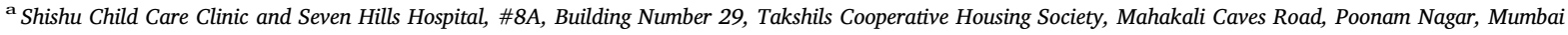 \\ 400093, India \\ ' Dr Sehgal's Clinic, B4/125 Safdarjung Enclave, New Delhi 110029, India \\ ${ }^{\mathrm{c}}$ Nestle India/ NNI, Mumbai, India
}

\section{A R T I C L E I N F O}

\section{Keywords:}

Functional constipation

Infant feeding

Stereospecific positioning of fatty acids

Human breast milk

Bowel habits in infants

\begin{abstract}
A B S T R A C T
Infants are frequently vulnerable to transient functional gastrointestinal disorders (FGIDs) including constipation. Evidence suggests stool frequency and consistency depends upon the various nutritional components including fats. Long chain saturated fats esterified at the sn- 1 and sn- 3 positions seen in vegetable oil-based infant formulas, are associated with the formation of calcium fatty acid soaps, contributing to constipation. Moreover, fatty acids esterified at sn-2 position, seen in breast milk, lead to formation of softer stools, reducing the chances of constipation. Thus, reducing palmitic acid from a vegetable oil-based infant formula appears to be the go-to solution to improve stool consistency.
\end{abstract}

\section{Introduction}

Infants grow and develop rapidly for which they require optimal nutritional support. However, during the course of development, they are frequently susceptible to transient functional GI disorders (FGIDs) of infancy. The most common FGIDs include Infantile colic, gastroesophageal reflux (GER), and functional constipation. ${ }^{1}, 2$ Globally, the prevalence of infantile colic has been reported to be about $10 \%-40 \%$, with a high prevalence at 6 weeks. ${ }^{3}$ Within the first 60 days of life, about $70 \%$ to $85 \%$ of infants have GER, which resolves without any treatment in $95 \%$ of the infants within 1 year of age. ${ }^{4},{ }^{5}$ Constipation manifests in almost $17 \%-40 \%$ of the infants during the first year of life. ${ }^{6}, 7$

\section{Functional constipation: a significant challenge}

Even though functional constipation is common during infancy, only $3 \%$ of the cases seek medical attention. ${ }^{5}, 6$

Rome IV criteria for constipation in infants and toddlers must include 1 month of at least 2 of the following in infants up to 4 year s of age:

- 2 or fewer defecations /week

- History of excessive stool retention

- History of painful or hard bowel movements
- Presence of a large fecal mass in the rectum

- History of a large diameter stool

In toilet trained children the following additional criteria may be used:

- At least 1 episode/week of incontinence after the acquisition of toileting skills

- History of large diameter stools which may obstruct the toilet ${ }^{8}$

In most cases, infants habitually withhold stools in an attempt to avoid defecation and the associated discomfort. Over time, the rectum may stretch to accommodate the retained fecal matter, weakening the rectum's propulsive power, manifesting as pain. ${ }^{5,}$,

While protocols are laid out for the treatment of constipation, prevention would however be desirable. This could be done by modification of the composition of infant formulas for those who cannot be breast fed and ensuring adequate fluid and fiber intake after 6 months of age once complementary feeding is started. Moreover, while colic and regurgitation resolve over time, constipation tends to persist and requires constant attention. Nutrition remains a vital arm that may alleviate the incidence of FGIDs, especially constipation. ${ }^{5,}$

\footnotetext{
* Corresponding author at: Nestle India Ltd, ICC chambers, Saki VIhar, Powai, Mumbai 400072, India.

E-mail address: Nikhil.Bangale@IN.nestle.com (N.R. Bangale).
} 


\section{Fats: an overview}

Fat is a vital macronutrient for infants and provides a concentrated source of energy to fuel growth and development in infants, matching the small stomach volume of an infant. In addition, fats support important metabolic and physiological functions, such as aiding in absorption of fat-soluble vitamins, supplying essential fatty acids, and acting as building blocks for hormones. They are also structural components of cell membranes and also precursors of various bioactive molecules. ${ }^{9}, 10$

Fatty acids (FA) are broadly classified into three types: saturated fatty acids (SFAs), monounsaturated fatty acids (MUFAs), and polyunsaturated fatty acids (PUFAs) based on the number of bonds. ${ }^{11}$

\subsection{Stereospecificity of fatty acids}

There are three main classes of fats: triglycerides, sterols, and phospholipids. Triglycerides, also known as dietary fats, are the most common type of lipids (98\%) found in the body and in foods. Triglycerides or triacylglycerols (TAGs) have a 3-carbon glycerol backbone to which 3 fatty acis are esterified. These glycerol carbons are stereospecifically numbered as sn-1, sn-2 and sn-3 (Fig. 1). ${ }^{12},{ }^{13}$ The position where the fatty acid is esterified to the glycerol backbone is stereospecifically numbered as sn-1, sn-2, or sn-3, and has a bearing onits digestion, absorption, metabolism, and distribution into tissues. ${ }^{14}$

\subsection{Digestion and absorption of fats}

Triacylglycerols (TAGs; or triglycerides) are hydrophobic molecules that undergo hydrolyzation and emulsification to very small droplets known as micelles before they are absorbed. This is facilitated by pancreatic lipase and bile salts. ${ }^{12}$

\subsubsection{Salivary phase}

Once ingested, the food is broken into small particles and is mixed with the enzyme lingual lipase, produced by serous lingual glands (von Ebner's glands). The role of lingual lipase in the digestion of triacylglycerols is limited since its activity is much slower compared to pancreatic lipase. Furthermore, lingual lipase acts in the stomach where the lipids amalgamate and form a separate phase from the surrounding environment. This restricts the opportunity for the lingual lipase to hydrolyze triacylglycerols. ${ }^{15}, 16$

\subsubsection{Gastric phase}

Hydrolysis of dietary lipids begins with gastric lipase, which splits the primary ester bonds. It preferentially catalyzes the hydrolysis of the fatty acid at the sn-3 position rather than that at sn-1 position and prefers TAGs with short- and medium-chain lengths, yielding free fatty acids (FFAs) and sn-1,2-diacylglycerols (DAGs). The medium-chain fatty acids liberated in the stomach can be absorbed directly into the portal blood and thus can affect hepatic metabolism (Fig. 2). ${ }^{12}$

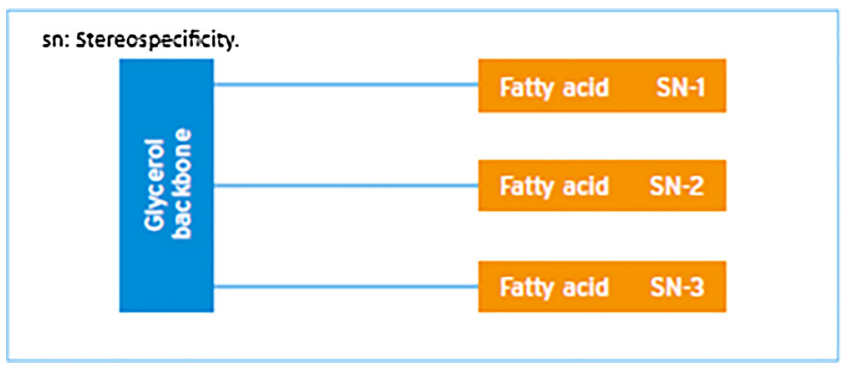

Fig. 1. The positional distribution of fatty acids (13).

\section{GASTRIC PHASE}

\section{Hydrolysis of TAGs}

Gastric lipase

Acts upon the sn-3 ester bond preferentially to sn-1 bonds

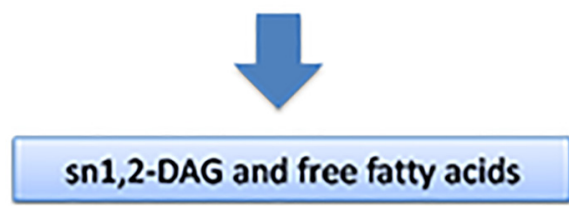

Fig. 2. Gastric phase of fat digestion (12).

\subsubsection{Intestinal phase}

The fat digestion continues in the intestine. Pancreatic lipase, which is secreted into the small intestine, splits the fatty acids from the sn1and sn-3positions of TAGs into 2-monoacylglycerols (2-MAGs) and FFAs as the major end products. Subsequently, MAGs are hydrolyzed to glycerol and FFAs (Fig. 3). ${ }^{12}$

\subsection{Impact of stereospecific positioning of fatty acids on bowel movements}

The formation and consistency of stools are closely related to dietary nutrients especially fats ${ }^{6}$ Certain fats are associated with the formation of calcium fatty acid soaps, leading to constipation and increased stool fat and calcium excretion, which can pose as a significant health challenge. ${ }^{17}$

Stereospecific positioning is of particular importance for LCSFAs such as palmitic acid, because palmitic acid is one of the primary components and has demonstrated poor absorption in its free form. This could be because of their melting point being above the body temperature. The unsaturated and short-chain saturated free fatty acids are

\section{INTESTINAL PHASE}

Fatty acids from the sn1- and sn2. position of TAGs

\section{Pancreatic lipase}

\section{2-MAGS and free fatty acids}

\section{Glycerols and free fatty acids}

Fig. 3. Intestinal phase of fat digestion (12). 
however well absorbed. The LCSFAs tend to form fatty acid soaps with minerals such as calcium or magnesium leading to hard stools. On the contrary, LCSFAs esterified at sn-2 position are better absorbed as MAGs. ${ }^{18-20}$

\section{Bowel habits in infants}

\subsection{Human breast milk}

Breast milk remains the ideal nutritional solution for infants. In addition, it is the most feasible and complete nourishment, offering enormous support to the digestive health of infants. The stools of a breastfed infant are softer and more frequent, compared with those in infants fed with cow's milk or soy preparations. Generally, constipation is rare in breastfed infants. ${ }^{21}$ Breast milk has specific and unique characteristics that help support bowel movements. They include the following: ${ }^{22-24}$

\begin{tabular}{cllll}
\hline $\begin{array}{l}\text { Whey:casein } \\
\text { rati- } \\
\text { o:60:40 }\end{array}$ & $\begin{array}{l}\text { Calcium:phosphorus } \\
\text { ratio:2:1 }\end{array}$ & $\begin{array}{l}\text { Optimal } \\
\text { osmolality }\end{array}$ & $\begin{array}{l}\text { Fat } \\
\text { composition }\end{array}$ & $\begin{array}{l}\text { Optimal } \\
\text { lactose } \\
\text { content }\end{array}$ \\
\hline
\end{tabular}

4.2. Fat structure and composition in human milk and its influence on infant health

Human milk (HM) supplies about $50 \%$ of the calories to a newborn as fat. More than $98 \%$ of this fat is available as triglycerides. The average fat content of HM ranges from 3.7 to $9.1 \mathrm{~g} / 100 \mathrm{kcal}$. Palmitic acid is the main saturated fatty acid, accounting for $20 \%$ to $25 \%$ of the fatty acids in mature HM (Table 1$) .{ }^{18},{ }^{25}$

The sn-2 positioning of fatty acids plays an important role in fat digestion and absorption. Human milk is a remarkable example of stereospecific positioning of fatty acids (Table 2). Data suggest that HM provides approximately $70 \%$ of its palmitic acid in the sn-2 position. Pancreatic lipase hydrolyzes the fatty acids in the sn- 1 and sn- 3 positions particularly, leaving palmitic acid as a sn-2 monoglyceride, which is usually absorbed well. The sn-2 MAGs are more polar and soluble. They are absorbed by passive diffusion and cannot form insoluble soaps with calcium and magnesium. Hence, HM causes less constipation and better absorption of calcium and magnesium. ${ }^{18-20},{ }^{26}$

\subsection{Fat structure and composition in a vegetable oil-based conventional infant formula and its influence on infant health}

Since human milk is considered as the gold standard for infants, its composition is used as a model for designing infant formula. Human milk has high palmitic acid content. Therefore, to match breast milk composition, palmitic acid rich formulas were designed initially. This

Table 1

Fatty acids and their composition in HM (25).

\begin{tabular}{ll}
\hline Fatty acid & Composition in Human Milk (\%) \\
\hline SFA & $45-46$ \\
Palmitic acid & $20-25$ \\
Stearic acid & $7.7-13.2$ \\
Butyric acid & 0.4 \\
Lauric acid & 5.8 \\
Monounsaturated fatty acid & $35-40$ \\
Polyunsaturated fatty acid & $14-19$ \\
Linoleic acid & $10-15$ \\
Arachidonic acid & $0.7-11$ \\
Alpha-linolenic acid & $0.1-2.0$ \\
Docosahexaenoic acid & $0.2-0.5$ \\
\hline
\end{tabular}

Source: European Food Safety Authority, 2014. did not turn out to be that simple. It was observed that palmitic acid from vegetable sources was stereospecifically different from that in breast milk. The palmitic acid from vegetable oils was mostly esterified at sn- 1 and sn- 3 positions while that from breast milk was esterified at sn-2 position. Digestion of triglycerides by pancreatic lipase affects sn- 1 and sn- 3 positions thus releasing free palmitic acid from both these sites. Free palmitic acid is less well absorbed and has a tendency to for form insoluble soaps with free calcium. This leads to decreased absorption of both fats and calcium and also results in harder and constipated stools. As a result, calcium essential for skeletal growth is lost. ${ }^{18,19,26,27}$

*Depending on the oil source used (Table 3).

Breastfed infants, therefore, have a higher mean frequency of defecation and tend to produce larger, softer stools when compared with infants fed with conventional vegetable oil-based formulas with a high palmitic acid content, esterified at the sn- 1 and sn-3 positions (Fig. 4). ${ }^{28},{ }^{29}$

Presence of

oligosaccharides

Calcium and fatty acid soaps were significantly related to stool solids and hardness score in both breastfed and vegetable oil-based formula-fed infants. Stools of vegetable oil-based formula-fed infants had a higher solid content and were significantly harder than those of breastfed infants due to differences in the fatty acid content, mainly palmitic acid and stearic acid. ${ }^{24}$

To meet the requirements of the rapidly expanding skeletal mass, growing infants require a bioavailable source of calcium. ${ }^{30}$ Calcium is therefore a vital nutrient in infancy. Moreover, studies suggest that most toddlers do not meet the estimated daily requirement for calcium. ${ }^{31}, 32$ The formation of calcium soaps and consequent calcium losses may have long-term implications on bone health in infants. ${ }^{30,33}$ Loss of LCSFAs as soaps, also leads to loss of energy. ${ }^{34}$

Thus, the effect of sn-2 positioning of fatty acids in human milk and vegetable oil based formulas has been summarized in Fig. 5.

\section{A nutritional solution closer to the benefits conferred by breast milk on stool consistency}

To improve fat and calcium bioavailability in conventional vegetable oil-based formula-fed infants and improve stool consistency, it seems logical to decrease the levels of free LCSFAs available for soap formation. By decreasing LCSFAs in formulas the fat and calcium bioavailability can be improved and constipation is decreased. ${ }^{35},{ }^{36}$

\subsection{Reducing the number of LCSFAs in sn1 and sn-3 positions}

Reducing palm oil and hence palmitic acid from a vegetable oil-based infant formula appears to be the go-to solution to improve stool consistency and calcium and fat absorption, closer to that of breast milk. ${ }^{18},{ }^{27}$

\subsubsection{Calcium and fat metabolic balance, and GI tolerance in term infants fed milk-based formulas with and without palm olein and palm kernel oils: a randomized, blind, crossover study}

A controlled, randomized, two treatment, double blinded crossover study assessed the calcium and fat metabolic balance in 33 healthy term infants fed with either (PALM), a formula-containing palm olein (44\% of total fat), palm kernel oil (21.7\%), and canola oil (18.5\%) as predominant fats or (noPALM), a formula-containing high oleic sunflower, coconut and soy oil. ${ }^{37}$

The study found that the percentage of calcium absorption was significantly higher in the formula with low levels of sn-1,3 LCSFAs than the formula with high levels of sn-1,3 LCSFAs $(p=.023)$. In 
Table 2

Palmitic acid profile in human milk (18-20).

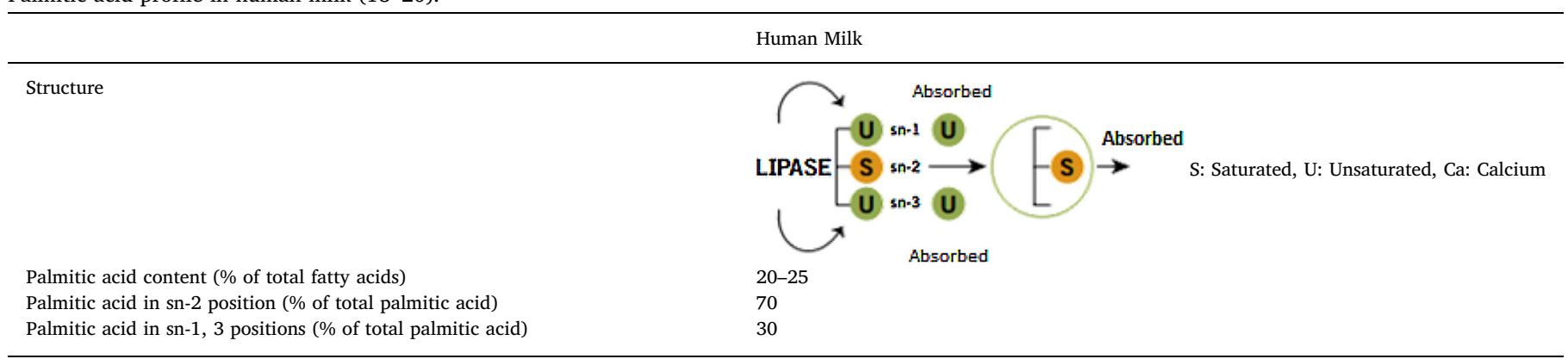

Table 3

Palmitic acid profile in conventional vegetable oil-based infant formula (18-20).

\begin{tabular}{l} 
Conventional vegetable oil-based infant formulas \\
\hline $\begin{array}{l}\text { Insoluble calcium soaps } \\
\text { excreted along with stools, } \\
\text { hence leading to hard stools }\end{array}$ \\
$\begin{array}{l}\text { Palmitic acid } \\
\text { content (\% of } \\
\text { total fatty } \\
\text { acids) } \\
\begin{array}{l}\text { Palmitic acid in } \\
\text { sn-2 position } \\
\text { (\% of total } \\
\text { palmitic acid) }\end{array}\end{array}$ \\
$\begin{array}{l}\text { Palmitic acid in } \\
\text { sn-1, } 3 \\
\text { positions (\% } \\
\text { of total } \\
\text { palmitic acid) }\end{array}$ \\
\hline Variable, close to human breast milk content
\end{tabular}

addition, the percentage of calcium retention was higher in the low levels of sn-1,3 LCSFAs ( $\mathrm{p}=.015)$, and it remained higher $(\mathrm{p}=.02)$ when calcium intake was used as a covariate (Fig. 6). ${ }^{37}$

Gastrointestinal tolerance was also assessed in the same study, and it was found that lower palmitic acid content had a positive effect with softer stool consistency. Furthermore, the percentage of loose stools was significantly higher $(\mathrm{p}=.002)$ during the tolerance phase and the percentage of formed stools was significantly lower $(\mathrm{p}<.001)$ during the metabolic phase with the lower palmitic acid content (Fig. 7). ${ }^{37}$

\subsubsection{Formula tolerance in post breastfed and exclusively formula-fed infants}

A study, bifurcated into two clinical evaluations, was conducted to assess the tolerance of two infant formulas that differed in composition. In study 1 , a total of 82 healthy, full-term infants who were exclusively breastfed were randomized at weaning to formula A with low palmitic acid content or formula B with high palmitic acid content. ${ }^{33}$

In study 2, a total of 87 healthy, full-term infants who were exclusively formula-fed at the time of study enrolment were fed a standard cow milk-based formula and then randomized to receive formula A or formula B for a 2-week period. Formula A had low palmitic acid content, whereas formula B had a high palmitic acid content. ${ }^{33}$

Infants weaned to formula B had significantly less frequent stools than those weaned to formula A. In both studies, infants fed with formula B experienced significantly firmer stools than did those fed with formula A ( $\mathrm{p}<.01$ ). In addition, infants fed with formula B in study 2 experienced a greater percentage of formed stools than those fed with formula A $(\mathrm{p}<.01)$ (Table 4). ${ }^{33}$

Softer stools have also been reported with low palmitic acid blend formulas as compared to high palmitic acid blends. ${ }^{29}$ Borschel in 2014 showed greater bone mineral content at day 84 (using body weight as a covariate) in formulas with lower palmitic acid content as compared to those with a high palmitic acid content. The stools were also softer in the former group. ${ }^{38}$

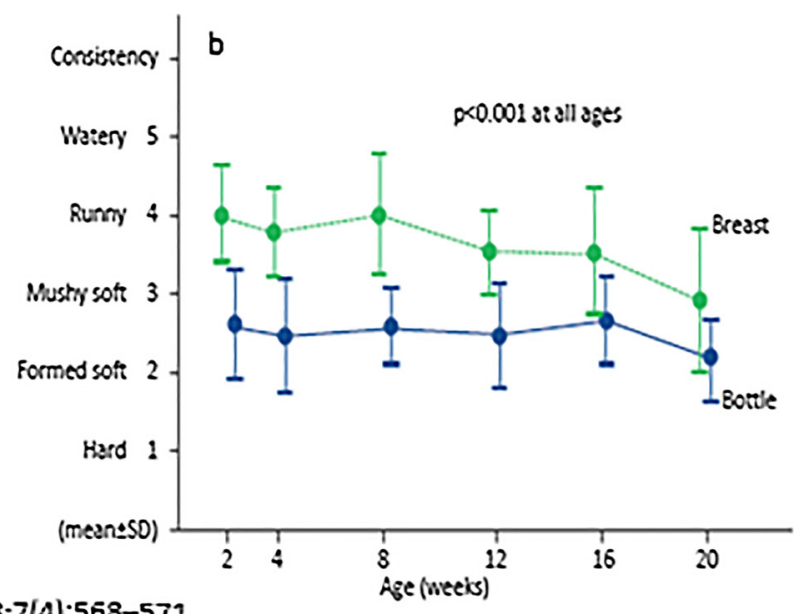

5ource: Weaver LT, et al. J Pediatr Gastroenterol Nutr. 1988;7[4]:568-571.

Fig. 4. (a) Higher mean frequency of defecation in breastfed infants (28). (b) The tendency to produce larger and softer stools by breastfed infants (28). 


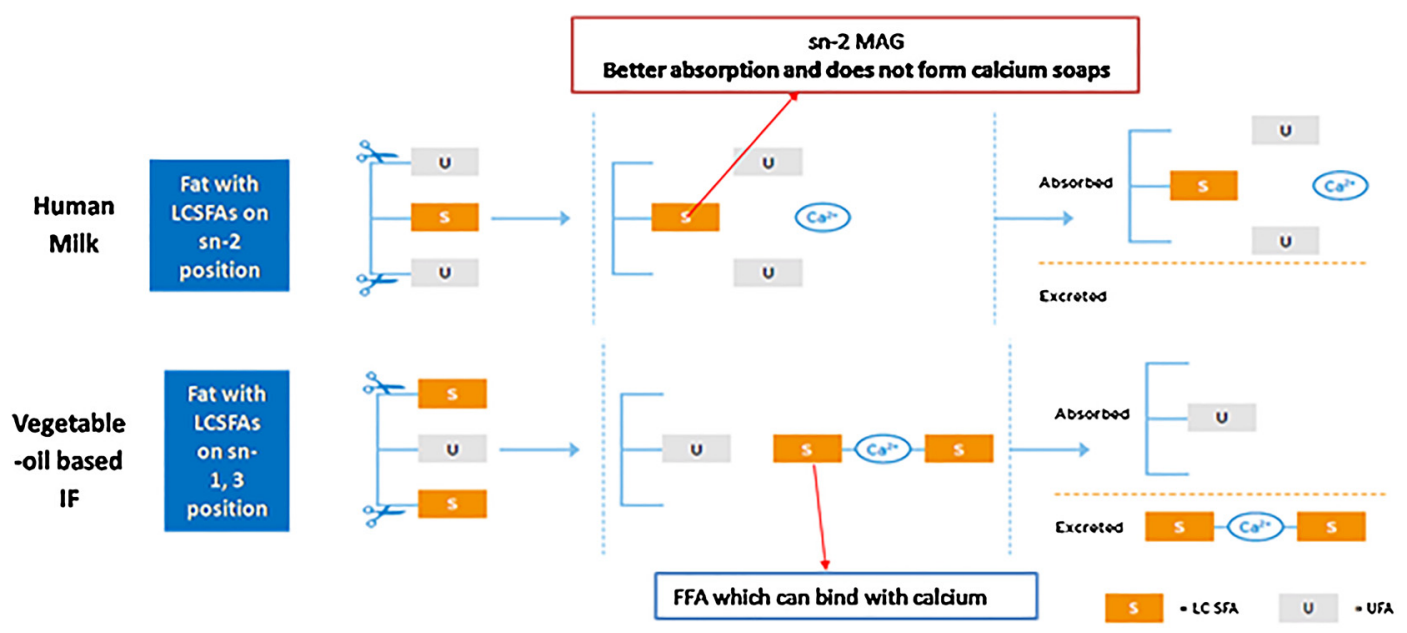

MAG: Mo noacyiglycero1; IF: Infant formula; LCSFA: Long chain saturated fatty acid; UJFA: Unsaturated fattyacids; Ca: Calcium; FFA: free fattyacids

Fig. 5. The sn-2 positioning of fatty acids in human milk and vegetable oil based formulas $(18,19,27)$.
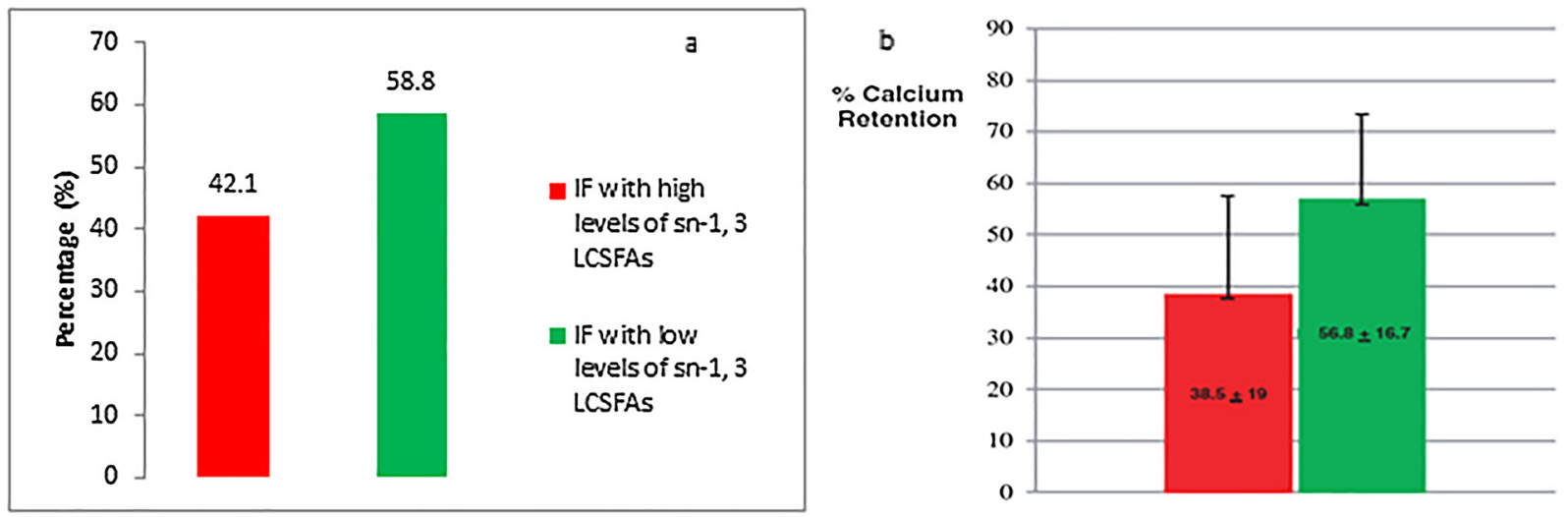

IF: Infaat formula; LCSFA: Long-chain saturated fattyacic.

Source: Leit MEQ.E.MC Pediaries. 21013;13:215.

Fig. 6. (a) Calcium absorption in high versus low levels of LCSFAs (37). (b) Calcium retention in high versus low levels of LCSFAs (37).

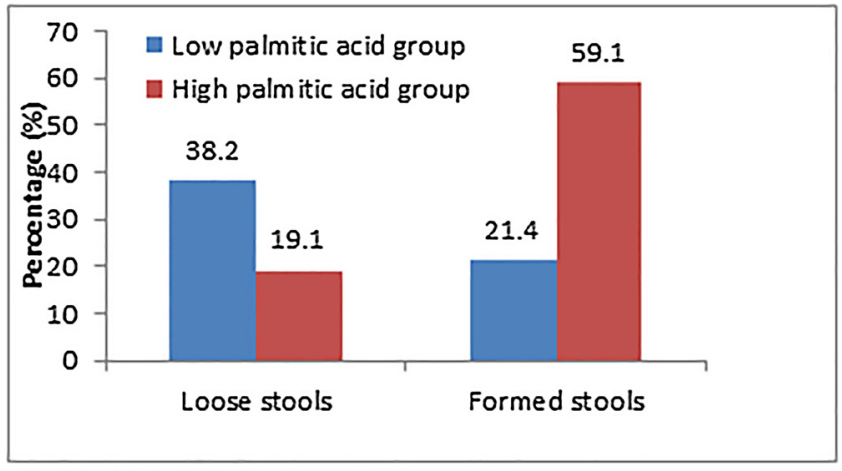

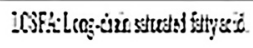

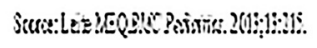

Fig. 7. Stool consistency in high versus low levels of LCSFAs (37).
Table 4

Softer stools and greater frequency of defecation with low levels of sn-1,3 LCSFAs (33).

\begin{tabular}{|c|c|c|c|c|}
\hline & \multirow{2}{*}{\multicolumn{2}{|c|}{$\begin{array}{l}\text { Study 1: Healthy, full-term } \\
\text { infants }(\mathrm{n}=82) \\
\text { Weaning period }\end{array}$}} & \multirow{2}{*}{\multicolumn{2}{|c|}{$\begin{array}{l}\text { Study 2: Healthy, full-term } \\
\text { infants }(\mathrm{n}=87) \\
\begin{array}{l}\text { Exclusive formula-feeding } \\
\text { period }\end{array}\end{array}$}} \\
\hline & & & & \\
\hline & $\begin{array}{l}\text { Formula A } \\
\text { (Low } \\
\text { palmitic } \\
\text { acid) }\end{array}$ & $\begin{array}{l}\text { Formula B } \\
\text { (High } \\
\text { palmitic acid) }\end{array}$ & $\begin{array}{l}\text { Formula A } \\
\text { (Low } \\
\text { palmitic } \\
\text { acid) }\end{array}$ & $\begin{array}{l}\text { Formula B } \\
\text { (High } \\
\text { palmitic acid) }\end{array}$ \\
\hline $\begin{array}{r}\text { Average stool } \\
\text { consistency } \\
\text { Stool consistency }\end{array}$ & $\begin{array}{l}2.3 \pm 0.1 \\
\% \text { of stools) }\end{array}$ & $2.5 \pm 0.1^{*}$ & $2.6 \pm 0.1$ & $3.0 \pm 0.1^{\mathrm{a}}$ \\
\hline Watery & $15 \pm 4$ & $9 \pm 4$ & $7 \pm 2$ & $1 \pm 0^{\mathrm{a}}$ \\
\hline Loose/mushy & $52 \pm 5$ & $34 \pm 5$ & $37 \pm 5$ & $19 \pm 4^{a}$ \\
\hline Soft & $25 \pm 4$ & $51 \pm 5^{*}$ & $41 \pm 6$ & $59 \pm 5^{a}$ \\
\hline Formed & $7 \pm 3$ & $5 \pm 2$ & $12 \pm 4$ & $20 \pm 4^{\mathrm{a}}$ \\
\hline Hard & 0 & $1 \pm 1$ & $2 \pm 1$ & $2 \pm 1$ \\
\hline
\end{tabular}

a Significantly different from formula A, $\mathrm{p}<.05$. Source: Lloyd B. Pediatrics. 1999;103:1-6. 
Table 5

Intake, excretion, and absorption of calcium and fats in two study groups (40).

\begin{tabular}{|c|c|c|c|c|c|c|c|c|}
\hline & \multicolumn{4}{|l|}{ Calcium } & \multicolumn{4}{|l|}{ Fats } \\
\hline & \multirow[t]{2}{*}{ Intake (mg/kg/day) } & \multirow[t]{2}{*}{ Fecal excretion (mg/kg/day) } & \multicolumn{2}{|l|}{ Absorption $^{\mathrm{a}}$} & \multirow[t]{2}{*}{ Intake ( $\mathrm{g} / \mathrm{kg} /$ day) } & \multirow[t]{2}{*}{ Fecal excretion (g/kg/day) } & \multicolumn{2}{|l|}{ Absorption $^{\mathrm{a}}$} \\
\hline & & & $\begin{array}{l}\text { (mg/kg/ } \\
\text { day) }\end{array}$ & (\% of intake) & & & (g/kg/day) & (\% of intake) \\
\hline Formula PO & $86(15.9)$ & $53.4^{\mathrm{b}}(12)$ & $32.6^{\mathrm{c}}(12.2)$ & $37.5^{\mathrm{b}}(11.5)$ & $5.64(1.04)$ & $0.55^{\mathrm{d}}(0.29)$ & $5.09^{\mathrm{e}}(1.08)$ & $90.0^{\mathrm{f}}(6.4)$ \\
\hline Formula HOS & $86.8(14.2)$ & $37.4(14.9)$ & $49.4(14.4)$ & $57.4(14.9)$ & $5.75(0.95)$ & $0.09(0.04)$ & $5.66(0.92)$ & $98.5(0.6)$ \\
\hline
\end{tabular}

Values are expressed as mean (SD).

PO: Palm olein; HOS: High-oleic safflower oil.

Source: Nelson BA. JACN. 1998;4:327-332.

a Intake minus fecal excretion.

b Significantly $(\mathrm{p}<.01)$ different from formula HOS.

c Significantly $(\mathrm{p}<.001)$ different from formula HOS.

d Significantly (p,0.001) different from Formula HOS.

e Significantly (p,0.05) different from Formula HOS.

f Significantly (p,0.01) different from Formula HOS.

Table 6

Additional evidence.

\begin{tabular}{|c|c|c|c|}
\hline \multirow[t]{2}{*}{ Evidence } & \multicolumn{2}{|c|}{ Estimated sum of sn-1, 3 LCSFAs (\% TAGs) (mean \pm SD) } & \multirow[t]{2}{*}{ Outcomes } \\
\hline & Test formula & Control formula & \\
\hline $\begin{array}{c}\text { Lopez-Lopez } \\
\text { et al. }{ }^{42}\end{array}$ & 19.7 & 28.3 & $\begin{array}{l}\text { - Lower amount of total fatty acids in stools after } 2 \text { months } \\
\text { - Lower amount of palmitic acid in stools after } 2 \text { months } \\
\text { - No difference in fecal calcium }\end{array}$ \\
\hline Nowacki et al. ${ }^{43}$ & $15.3 \pm 0.8$ & $28.4 \pm 2.0$ & $\begin{array}{l}\text { - No difference in the amount of total fatty acids soaps in stools } \\
\text { - Lower palmitic acid soaps } \\
\text { - No difference in fecal excretion of calcium } \\
\text { - No difference in stool consistency (predominantly mushy/soft category) } \\
\text { - No difference in stool frequency }\end{array}$ \\
\hline Yao et al. ${ }^{29}$ & $15.3 \pm 0.8$ & $28.4 \pm 2.0$ & $\begin{array}{l}\text { - Lower amount of total FA soaps and saturated FAs (lauric, myristic, palmitic, and stearic } \\
\text { acids) in stools } \\
\text { - No difference in the amount of calcium in stools } \\
\text { - Higher mushy soft stools and lower formed stools } \\
\text { - No difference in the daily number of bowel movements }\end{array}$ \\
\hline
\end{tabular}

LCSFA: Long-chain saturated fatty acid; TAG: Triacylglycerols; SD: Standard deviation.

5.1.3. Lower calcium absorption in infants fed casein hydrolysate- and soy protein-based infant formulas containing palm olein versus formulas without palm olein

Cow milk based formulas have most of the calcium inherent to the protein source. In contrast casein hydrolysate-based formulas (CHF) or soy protein-based formulas(SPF) no appreciable calcium is supplied by protein. Therefore, they need to be fortified with calcium and phosphorus. $^{30}$

Two randomized, blind, crossover balance studies were conducted to compare fat and calcium absorption in infants fed with commercially available CHF with or without palm olein $(n=10)$ and commercially available SPF with or without palm olein $(n=12)$. All formulas contained added calcium salts. ${ }^{30}$

The study suggested that calcium absorption was significantly lower with formula having palm olein than that without palm olein (237 vs. $441 \mathrm{mg} / \mathrm{kg} / \mathrm{day} ; \mathrm{p}<.01$ ), and calcium excretion was significantly higher in the palm olein group than the non-palm olein group (55 vs. $30 \mathrm{mg} / \mathrm{kg}$ /day; $\mathrm{p}<.01$ ). Further, calcium absorption was significantly lower in the formula with palm olein than that without palm olein (107 vs. $176 \mathrm{mg} / \mathrm{kg} / \mathrm{day} ; \mathrm{p}<.05$ ), and calcium excretion was higher in the palm olein group than in the non-palm olein group $(58 \mathrm{vs.} 44 \mathrm{mg} / \mathrm{kg}$ / day; non-significant). Hence, palm olein levels similar to palmitic acid content of HM significantly reduce calcium absorption in both hydrolyzed protein-based and soy protein-based infant formulas that use mineral salts as a primary source of calcium. ${ }^{30}$

Nelson et al., in 1996 showed that fat is less well absorbed from a mixture of $53 \%$ palm olein and $47 \%$ soy oil than a mixture of $60 \%$ soy oil and $40 \%$ coconut oil and that calcium absorption is less from formula containing palm olein oil. ${ }^{39}$

\subsubsection{Absorption of fat and calcium by infants fed a milk-based formula containing palm olein}

Ten infants were randomized to receive either formula PO containing palm olein (PO; 45\%), soy (20\%), coconut oil (20\%), and higholeic sunflower oils $(15 \%)$ or formula HOS containing high-oleic safflower oil (HOS; 42\%), in addition to coconut and soy oils (30\% and $28 \%$, respectively), and no palm olein. Formula PO was a high palmitic acid formula with an LCSFA content of $25.2 \% \pm 2.1 \%$ of total TAG and formula HOS was a low palmitic acid formula with an LCSFA content of $13 \% \pm 0.5 \%$ of TAGs. $^{40}$

The study results suggested that intake of calcium was similar with both the formulas. In addition, fecal excretion of calcium was significantly higher with formula PO $(\mathrm{p}=.002)$ than with formula HOS. Moreover, calcium absorption was significantly lower $(\mathrm{p}=.001)$ with formula PO than with formula HOS. In addition, mean fecal excretion of fat was higher when Formula PO was fed than when Formula HOS was fed $(0.5560 .29$ vs. $0.0960 .04 \mathrm{~g} / \mathrm{kg} / \mathrm{day} ; \mathrm{p}<0.001)$. Hence $\%$ fat absorption was lower with PO than with HOS (90.066.4 vs. $98.560 .6 \%$ of intake; $\mathrm{p}<0.01$ ). (Table 5). ${ }^{40}$

Koo et al also suggested that healthy term infants fed a formula containing PO as predominant oil in the fat blend has significantly lower bone mineral content and bone mineral density than those fed 
formula without PO. The inclusion of PO in infant formula at levels needed to provide a fatty acid profile similar to that of human milk leads to lower mineralization. ${ }^{41}$

Additional evidence remains in coherence with the aforementioned findings (Table 6). A study conducted by Lopez-Lopez et al. in 2011 showed that high palmitic acid in sn-2 position lowered the amount of total fatty acids and palmitic acid in stool after 2 months. ${ }^{42}$ Nowacki et al. in 2014 suggested that high palmitic acid in sn-2 position lowered the formation of palmitic acid soaps. ${ }^{43}$

\section{Conclusion}

The stereospecific distribution of LCSFA on glycerol backbone in vegetable oil-based infant formulas is different from HM. However, contrary to HM, in which the LCSFA is esterified predominantly in the sn-2 position, vegetable oil-based infant formula and animal milk contain LCSFA predominantly in the sn- 1 and sn- 3 positions. Moreover, it is clear that LCSFA at sn-2 is better absorbed as MAGs and unabsorbed LCSFAs from sn-1 and sn-3 bind to calcium and tend to form insoluble calcium soaps. This may contribute to the stool hardness and also result in lower calcium and fat retention, leading to overall detrimental consequences to an infant's health. A nutritional solution closer to the benefits conferred by breast milk is required to help support stool consistency. Thus, reducing the total amount of palmitic acid by removing palm olein conventional infant formulas, thereby reducing the amount of sn-1,3 LCSFAs ( $<13 \%$ of total fat), may promote higher calcium and fat absorption. In addition, it may promote stool pattern similar to that in breastfed infants.

\section{Funding}

The program is funded by Nestle Nutrition Institute, South Asia.

\section{Conflict of interest}

Authors, VM, SKS, none to declare.

Authors NRB is employee of Nestle India.

\section{Acknowledgements}

We would like to acknowledge BioQuest Solutions for their support in editorial services.

\section{References}

[1]. Vandenplas Y, Abkari A, Bellaiche M, et al. Prevalence and health outcomes of functional gastrointestinal symptoms in infants from birth to 12 months of age. $J$ Pediatr Gastroenterol Nutr. 2015;61:531-537.

[2]. Rasquin-Weber A, Hyman P, Cucchiara S, et al. Childhood functional gastrointestinal disorders. Gut. 1999;45:1160-1168.

[3]. Johnson J, Cocker K, Chang E. Infantile colic: recognition and treatment. Am Fam Physician. 2015;92:577-582.

[4]. Shah B, Padbury J. 50 years ago in The Journal of Pediatrics: the behavior of the lower esophageal sphincter in infants and its relationship to gastroesophageal regurgitation. J Pediatr. 2014;164:88

[5]. Biggs W, Dery W. Evaluation and treatment of constipation in infants and children. Am Fam Physician. 2006;73:469-477.

[6]. Evaluation and treatment of constipation in infants and children. $J$ Pediatr Gastroenterol Nutr. 2006;43:e1-13.

[7]. Poddar U. Approach to constipation in children. Indian Pediatrics 2016;53:319-327.

[8]. Zeevenhooven J, Koppen I, Benninga M. The New Rome IV Criteria for functional gastrointestinal disorders in infants and toddlers. Pediatr Gastroenterol Hepatol Nutr. 2017;20:1-13.

[9]. Milner J, Allison R. The role of dietary fat in child nutrition and development: summary of an ASNS Workshop. J Nutr. 1999;129:2094-2105.

[10]. Delplanque. Lipid quality in infant nutrition: current knowledge and future opportunities. J Pediatr Gastroenterol Nutr. 2015;61:8-17.
[11]. Food and Agricultural Organization. Fats and fatty acids in human nutrition report of an expert consultation Geneva 2008; 2008.

[12]. Christophe AB. Structural effects on absorption, metabolism, and health effects of lipids. 6th edIn: Shahidi F, ed. Bailey's industrial oil and fat products. vol. 6. New Jersey: John Wiley \& Sons; 2005.

[13]. Karupiah T. Effects of stereospecific positioning of fatty acids in triacylglycerol structures in native and randomized fats: a review of their nutritional implications. Nutr Metabol. 2007;4:16.

[14]. Berry SEE. Triacylglycerol structure and interesterification of palmitic and stearic acid-rich fats: an overview and implications for cardiovascular disease. Nutr Res Rev. 2009;22:3-17

[15]. Lingual lipase. Gastroenterology. 1986;90:1290-1297.

[16]. Liao T, Hamosh P, Hamosh M. Fat digestion by lingual lipase: mechanism of lipolysis in the stomach and Upper small intestine. Pediatr Res. 1984;18:402-409.

[17]. Xinias I, Mavroudi A. Constipation in childhood. An update on evaluation and management. Hippokratia. 2015;19:11-19.

[18]. Havlicekova Z, Jesenak M, Banovcin P, et al. Beta-palmitate - a natural component of human milk in supplemental milk formulas. Nutrition J. 2016;15:28.

[19]. Innis SM. Dietary triacylglycerol structure and its role in infant nutrition. Adv Nutr. $2011: 2: 275-283$

[20]. Lammi-Keefe CJ, Jensen RG. Lipids in human milk: a review. 2: composition and fat-soluble vitamins. J Pediatr Gastroenterol Nutr. 1984;3:172-198.

[21]. Riordan J, ed. Breastfeeding and human lactation. 3rd ed. Massachusetts: Jones and Barlett Publishers; 2005.

[22]. Leung AKC, Sauve RS. Breast is best for babies. J National Med Assoc 2005;97:1010-1019.

[23]. Pearson F, Johnson MJ, Leaf AA. Milk osmolality: does it matter? Arch Dis Childhood-Fetal Neonat Ed. 2011;98:F166-1669.

[24]. Quinlan PT, Lockton S, Irwin J, et al. The relationship between stool hardness and stool composition in breast- and formula-fed infants. J Pediatr Gastroenterol Nutr. 1995;20:81-90.

[25]. European Food Safety Authority (EFSA). Scientific opinion on the essential composition of infant and follow-on formulae. EFSA Panel on dietetic products, nutrition and allergies (NDA). EFSA J. 2014;12:3760.

[26]. Lasekan J, Husteada D, Masor M, et al. Impact of palm olein in infant formulas on stool consistency and frequency: a meta-analysis of randomized clinical trials. Food Nutrition Res. 2017;16:1-10.

[27]. Huang YS, Sinclair AJ. Lipids in infant nutrition. Illinois: AOCS Press; 1998.

[28]. Weaver LT, Ewing G, Taylor LC. The bowel habit of milk-fed infants. J Pediatr Gastroenterol Nutr. 1988;7:568-571.

[29]. Yao M. Effects of term infant formulas containing high sn-2 palmitate with and without oligofructose on stool composition, stool characteristics, and bifidogenicity. J Pediatr Gastroenterol Nutr. 2014;59:440-448.

[30]. Ostrum KM, Borschel MW, Westcott JE, et al. Lower calcium absorption in infants fed casein hydrolysate- and soy protein-based infant formulas containing palm oleinversus formulas without palm olein. JACN. 2002;21:564-569.

[31]. Hilger J, Goerig T, Weber P, et al. Micronutrient intake in healthy toddlers: a multinational perspective. Nutrients. 2015;7:6938-6955.

[32]. Hamner HC, Perrine CG, Scanlon KS. Usual intake of key minerals among children in the second year of life, NHANES 2003-2012. Nutrients. 2016;8:468.

[33]. Lloyd B, Halter RJ, Kuchan MJ, et al. Formula tolerance in post-breastfed and exclusively formula-fed infants. Pediatrics. 1999;103:1-6.

[34]. Nowacki J, Lee HC, Lien R, et al. Stool fatty acid soaps, stool consistency and gastrointestinal tolerance in term infants fed infant formulas containing high sn-2 palmitate with or without oligofructose: a double-blind, randomized clinical trial. Nutr J. 2014;13:2-11

[35]. Lien EL, Boyle FG, Yuhas R, et al. The effect of triglyceride positional distribution on fatty acid absorption in rats. J Pediatr Gastroenterol Nutr. 1997:25:167-174.

[36]. Hunter JE. Studies on effects of dietary fatty acids as related to their position on triglycerides. Lipids. 2001;36:655-688.

[37]. Leite MEQ, Lasekan J, Baggs G, et al. Calcium and fat metabolic balance, and gastrointestinal tolerance in term infants fed milk-based formulas with and without palm olein and palm kernel oils: a randomized blinded crossover study. BMC Pediatr. 2013;13:215

[38]. Borschel M, Choe Y, MAS1, Kajzer J. Growth of healthy term infants fed partially hydrolyzed whey-based infant formula: a randomized, blinded, controlled trial. Clin Pediatr. 2014;53:1375-1382.

[39]. Nelson SE, Rogers RR, Frantz JA, et al. Palm olein in infant formula: absorption of fat and minerals by normal infants. Am J Clin Nutr. 1996:64:291-296.

[40]. Nelson BA, Joan A. Absorption of fat and calcium by infants fed a milk-based formula containing palm olein. JACN. 1998;4:327-332

[41]. Koo W, Hammami M, Margeson D, et al. Reduced bone mineralization in infants fed Palm olein-containing formula: a randomized, double-blinded, prospective trial. Pediatrics. 2003;111:1017-1023.

[42]. López-López A, Castellote-Bargalló AI, Campoy-Folgoso C, et al. The influence of dietary palmitic acid triacylglyceride position on the fatty acid, calcium and magnesium contents of at term newborn faeces. Early Hum Dev. 2001;65:S83-S94.

[43]. Nowacki J, Lee HC, Lien R, et al. Stool fatty acid soaps, stool consistency and gastrointestinal tolerance in term infants fed infant formulas containing high sn-2 palmitate with or without oligofructose: a double-blind, randomized clinical trial. Nutrition J. 2014;13:105. 